\title{
TRCI50094, a Novel Mitochondrial Modulator, Reduces Cardio-Metabolic Risk as an Add-On Treatment: a Phase-2, 24-Week, Multi-Center, Randomized, Double-Blind, Clinical Trial
}

\author{
Deepa Joshi', Prashant GJ', Shohini Ghosh', Anookh Mohanan', Shashank Joshi², \\ Viswanathan Mohan $\mathbb{D}^{3}$, Subhankar Chowdhury ${ }^{4}$, Chaitanya Dutt' ${ }^{1}$, Nikhil Tandon ${ }^{5}$ \\ 'Torrent Pharmaceuticals Ltd., Ahmedabad, Gujarat, India; ${ }^{2}$ Lilavati Hospital, Mumbai, India; ${ }^{3}$ Dr. Mohan's Diabetes Specialities Centre (Madras \\ Diabetes Research Foundation), Tamil Nadu, India; ${ }^{4}$ Department of Endocrinology, Institute of Post-Graduate Medical Education and Research and \\ Seth Sukhlal Karnani Memorial Hospital, Kolkata, India; ${ }^{5}$ Department of Endocrinology, All India Institute of Medical Sciences, New Delhi, India
}

Correspondence: Deepa Joshi, Research \& Development, Torrent Pharmaceuticals Ltd., Ahmedabad, Gujarat, India, Tel + 9I 797I3I557I, Email deepajoshi@torrentpharma.com

Background: TRC150094, a novel mitochondrial modulator, reduces insulin resistance and is expected to improve the trinity of dysglycemia, dyslipidemia, and hypertension. In this multi-dose phase-2 study, we evaluated the safety and efficacy of TRC150094 in diabetic subjects with dyslipidemia receiving standard of care.

Methods: A randomized, multicenter, double-blind, placebo-controlled, parallel-group, Phase 2 study was conducted in 225 subjects from July 2013 to August 2015. The key inclusion criteria were body mass index of $23-35 \mathrm{~kg} / \mathrm{m}^{2}$, age between 30 and 65 years, fasting glucose of $\geq 126$ or glycated hemoglobin (HbAlc) of $\geq 6.4 \%$ stabilized on treatment with $\leq 2$ oral hypoglycemic agents, apolipoprotein-B (apo-B) $\geq 100 \mathrm{mg} / \mathrm{dL}$, serum triglyceride (TG) $\geq 150 \mathrm{mg} / \mathrm{dL}$, systolic blood pressure (SBP) $\geq 130 \mathrm{mmHg}$, and diastolic blood pressure (DBP) $\geq 85 \mathrm{mmHg}$ with/without antihypertensive treatment. The subjects were randomly assigned to one of three TRC150094 doses $(25,50$, or $75 \mathrm{mg})$ or placebo for 24 weeks. The outcomes assessed included fasting plasma glucose (FPG), insulin, mean arterial blood pressure (MAP), and apoB. In addition, safety and tolerability were assessed.

Results: A reduction for dose up to $50 \mathrm{mg}$ was noted for FPG in the range of 13.9 to $21.7 \mathrm{mg} / \mathrm{dL}$ (p $<0.05$ for TRC150094 25 and 50 $\mathrm{mg}$ ), fasting insulin reduction in the range 2.7 to $6.0 \mathrm{mU} / \mathrm{L}$ (all doses, $\mathrm{p}>0.05$ ), and improved HOMA-IR ( -2.0 to -2.5$)$ (all doses, $\mathrm{p}>$ 0.05 ) compared to placebo after 24 weeks of treatment. Furthermore, a significant reduction in MAP in the range 3.1 to $4.2 \mathrm{mmHg}(\mathrm{p}<$ 0.05 for TRC150094 25 and $75 \mathrm{mg}$ ) was noted. In addition, TRC150094 treatment was weight neutral, had a favorable effect on lowering atherogenic lipid fractions, including non-HDL cholesterol $(-6.8 \mathrm{mg} / \mathrm{dL}$ at $50 \mathrm{mg}$ dose). Adverse events were mild to moderate in nature and not dose-related. One adverse event not related to treatment led to the discontinuation of the study. Overall, TRC150094 was safe and well tolerated for up to 24 weeks.

Conclusion: In this study, TRC150094 treatment in the dose range of 25 to $50 \mathrm{mg}$ showed improvement in various components of CMBCD, ie, dysglycemia, dyslipidemia, and hypertension.

Trial Registration: This study was registered in the Clinical Trial Registry of India. Trial registration number: CTRI/2013/03/ 003444. Date of registration: 4th March 2013.

Keywords: cardiometabolic-based chronic disease, mitochondrial modulator, type 2 diabetes, non-HDL cholesterol, hypertension, dyslipidemia

\section{Background}

In recent times, type 2 diabetes (T2D) and cardiovascular disease (CVD) are increasingly recognized as "dysglycemia-based chronic disease" and "cardiometabolic-based chronic disease" (CMBCD). These provide a basis for early and sustainable, evidence-based targets which can promote cardio-metabolic health and mitigate the progression of cardiovascular disease. ${ }^{1}$

Received: 21 July 2021

Accepted: 3 November 2021

Published: 25 February 2022 
The upstream metabolic drivers of CMBCD, adiposity and dysglycemia interact at the level of insulin resistance (IR). ${ }^{2}$ Further, evidence suggests that the derangement of metabolic flexibility, ie, inability to respond/adapt to conditional changes in metabolic demand is a common thread linking IR to metabolic drivers of CMBCD. ${ }^{3}$

In the REAL YOUNG study, more than 15,000 young individuals (18-45 years) with a diagnosis of dyslipidemia and receiving treatment of dyslipidemia and/or diabetes and/or hypertension in India, 87.1\% of the population had one or multiple comorbidities, including all three diagnoses (39.1\%), dyslipidemia with diabetes (33.6\%), and dyslipidemia with hypertension (14.4\%). ${ }^{4}$ Total costs of illness (direct and indirect) and economic burden of cardiometabolic diseases (CMD; hypertension, stroke, coronary heart disease, T2D and its complications, and chronic kidney disease) based on a large survey of three major cities of South Asia was International dollars (Int\$) 708. The total annual costs per patient for individual and comorbid CMDs varied considerably from Int $\$ 358$ to Int $\$ 2342$, accounting for $40 \%$ of per capita expenditures. $^{5}$

CMBCD healthcare burden could be reduced, targeting the upstream drivers of metabolic inflexibility, ie, IR, dysglycemia, dyslipidemia, and hypertension, potentially preventing micro- as well as macro-vascular complications. There is an urgent need to identify interventions that can be applied at each CMBCD stage, depending on pathophysiological targets and clinical goals. ${ }^{6}$ If implemented successfully, an early preventive cardiometabolic approach would facilitate earlier and more effective intervention, in contrast with current practice standards that focus solely on dysglycemia and downstream CVD complications.

TRC150094, a novel mitochondrial modulator, has been studied extensively in preclinical and phase-1 studies and has demonstrated an ability to restore the metabolic inflexibility caused by mitochondrial dysfunction. ${ }^{7-10}$ In preclinical studies, administration of TRC150094 to rats fed with high-fat diet for 4 weeks led to increased activity of electron transport chain complex II and V and increased mitochondrial fatty acid import and oxidation, leading to increased energy expenditure. ${ }^{7,8}$ Data from Zucker fatty and spontaneously hypertensive rat models (ZSF1) studied for 24 weeks have shown that TRC150094 improves insulin sensitivity and attenuates atherogenic dyslipidemia, dysglycemia, high blood pressure, and visceral adiposity. ${ }^{9}$ Further, extensive safety evaluation, including long-term toxicity studies on rodent and non-rodent species in which target-related effects on thyroid axis, cardiac, bone, and cartilage were specifically monitored, did not reveal study drug-related changes in the biomarkers or histology. In addition, the respiratory, central nervous system, and cardiovascular safety evaluation in sensitive animal models (either rodent or dog) confirmed a wide safety margin. In the Phase-1 study, TRC150094 was found to be safe and well tolerated when administered orally in the dose ranging from 5 to $400 \mathrm{mg}$ in the single and multiple ascending dose studies across different ages, gender, and races in overweight and obese subjects. Furthermore, its half-life ranged from 15 to 18 hours, making it suitable for once-daily dosing. In addition, the pharmacokinetics of TRC150094 were linear with no clinically significant food effect, and its metabolites suggested a lesser likelihood of drug-drug interactions. ${ }^{10}$ Further, a significant reduction was noted in apolipoprotein B (apo B) levels at $50 \mathrm{mg}$ compared to placebo, but not at a higher dose of $150 \mathrm{mg}$. Exploratory analysis for pharmacodynamic markers in overweight and obese individuals demonstrated a trend towards improvement in insulin sensitivity (HOMA-IR, MATSUDA index) and reduction in triglycerides and hepatic fat. ${ }^{10}$ These promising results in preclinical and Phase-1 studies warranted further clinical development in the Phase-2 study for exploring efficacy and safety of TRC150094 at doses 25,50, and $75 \mathrm{mg}$ with a treatment duration of 24 weeks.

The primary objective of the study was to evaluate the efficacy and safety of TRC150094 vs placebo as an add-on to the standard of care $(\mathrm{SoC})$ in the treatment of cardio-metabolic risk in overweight/obese diabetic subjects with dyslipidemia, to estimate the dose to be taken forward into phase- 3 clinical trials. We report the results of the phase- 2 trial for the efficacy and safety of TRC150094 versus placebo treatment for 24 weeks.

\section{Methods}

\section{Study Design}

This was a randomized, multicentre, double-blind, placebo-controlled, parallel-group, phase 2 study conducted from July 2013 to August 2015 in 17 centers in India and was registered at the Clinical Trial Registry of India (CTRI/2013/03/ 003444). The study was conducted in accordance with the International Council for Harmonization-Good Clinical 
Practice (ICH-GCP) guidelines, the Declaration of Helsinki, and applicable regulatory requirements in India. The study was initiated after obtaining the approval of the Drug Controller General of India (DCGI; F.No.12-196/09 DC, Dec 21, 2012), Independent/Institutional Ethics Committee (IEC) of each site. Refer to the details of IEC in Table 1. All subjects provided written informed consent before study procedures were commenced. The study design is depicted in Figure 1.

Table I Details of Institutional/Independent Ethics Committee

\begin{tabular}{|c|c|c|}
\hline $\begin{array}{l}\text { Sr } \\
\text { No }\end{array}$ & $\begin{array}{l}\text { Name of Principal } \\
\text { Investigator }\end{array}$ & Ethics Committee Address \\
\hline I & Dr. Paramesh Shamanna & $\begin{array}{l}\text { Banglore Clinisearch Institutional Ethical Review Board, \#416, 4th Cross, 2nd Block, Kalyan Nagar, Bangalore- } \\
560,043 \text {, Karnataka, India }\end{array}$ \\
\hline 2 & Dr. Naveen Jamwal & $\begin{array}{l}\text { Institutional Ethics Committee, MV Hospital, and Research Centre, 3/4/30 Mirza Mandi, Chowk, Lucknow- } \\
\text { 226,003, Uttar Pradesh, India }\end{array}$ \\
\hline 3 & Dr. Shrikant Deshpande & $\begin{array}{l}\text { Ashirwad Ethics Committee, Ashirwad Hospital \& Research Centre, Maratha Section, Near Jijamata Udyan, } \\
\text { Ulhasnagar 42I,004, Maharashtra, India }\end{array}$ \\
\hline 4 & Dr. K. D. Modi & $\begin{array}{l}\text { Independent Ethics Committee, Medwin Hospital, Raghava Ratna Towers, Chirag Ali Lane, Nampally, } \\
\text { Hyderabad, Andhra Pradesh-500,00I, India }\end{array}$ \\
\hline 5 & Dr. Neeta Deshpande & $\begin{array}{l}\text { Ethics Committee, Belgaum Diabetes Centre, \#24I, Devaki Building, Ranade Road, Tilakwadi, Belgaum- } \\
590,006 \text {, Andhra Pradesh, India }\end{array}$ \\
\hline 6 & Dr. S. R. Arvind & $\begin{array}{l}\text { Diacon Hospital Ethics Committee, Diacon Hospital, Diabetes Care \& Research Centre, No. 359-360, 19th } \\
\text { Main, Ist block, Rajajinagar, Bangalore-560,010, Karnataka, India }\end{array}$ \\
\hline 7 & Dr. R. Balamurugan & $\begin{array}{l}\text { Institutional Ethics Committee, Kovai Diabetes Speciality Centre \& Hospital, No.I5, Vivekananda Road, } \\
\text { Ramnagar, Coimbatore-64I,009, Kerala, India }\end{array}$ \\
\hline 8 & Dr. Sunil Gupta & $\begin{array}{l}\text { Ethics Committee, Sunil's Diabetes Care n Research Centre, 42, Lendra Park, Ramdaspeth, Nagpur-440,0I0 } \\
\text { Maharashtra, India }\end{array}$ \\
\hline 9 & Dr. Yogesh Kadam & $\begin{array}{l}\text { Ethics Committee of Biniwale Clinic, 852/I, Dinkar Baug Apartment, Bhandarkar Institute Road, Pune-4II,004, } \\
\text { Maharashtra, India }\end{array}$ \\
\hline 10 & Dr. Sreenivasa Murthy & $\begin{array}{l}\text { Lifecare Ethics committee, No. 2253, MCN Complex, Kodigehalli Main Road, Sahakar Nagar, Bangalore- } \\
560,092 \text {, Karnataka, India }\end{array}$ \\
\hline II & Dr. Mala Dharmalingam & $\begin{array}{l}\text { Ethics Committee on Human Research, Bangalore Endocrinology \& Diabetes Research Centre, No-35, 5th } \\
\text { Cross, Malleshwaram Circle, Bangalore-560,003, Karnataka, India }\end{array}$ \\
\hline 12 & Dr. Shivakumar B. R. & $\begin{array}{l}\text { Synapse Ethics Committee, No. 8, 5th Mariappa Road, Kullappa Circle, St. Thomas Town Post, Bangalore- } \\
\text { 560,084, Karnataka, India }\end{array}$ \\
\hline 13 & Dr. Shreerang Godbole & $\begin{array}{l}\text { Ethics Committee (INSTRIDE), Flat No. I and 2, Chandraprabha, SNI27/I, Mahaveer Park, I.T.I. Road, Opp. } \\
\text { Sarjaa Hotel, Aundh, Pune- } 4 \text { II,007, Maharashtra, India }\end{array}$ \\
\hline 14 & Dr. Vinayak Kale & Ethics Committee, Lokmanya Medical Research Centre, 3I4/B, Chinchwad, Pune-4II,033, Maharashtra, India \\
\hline 15 & Dr. Shailesh Pitale & $\begin{array}{l}\text { Independent Ethics Committee, C/O Navjeevan Nursing Home, 20/I, Dr. Khare Marg, Dhantoli, Nagpur- } \\
\text { 440,012, Maharashtra, India }\end{array}$ \\
\hline 16 & Dr. Shehla Shaikh & Clinical Ethics Forum, Sai Prasad, Ist Floor, Flat no. 6, I25/A, Sion(West), Mumbai-400,022, Maharashtra, India \\
\hline 17 & Dr. V. Mohan & $\begin{array}{l}\text { Institutional Ethics Committee, Madras Diabetes Research Foundation, \#4, Conran Smith Road, Gopalapuram, } \\
\text { Chennai- } 600,086 \text {, Tamil Nadu, India }\end{array}$ \\
\hline
\end{tabular}




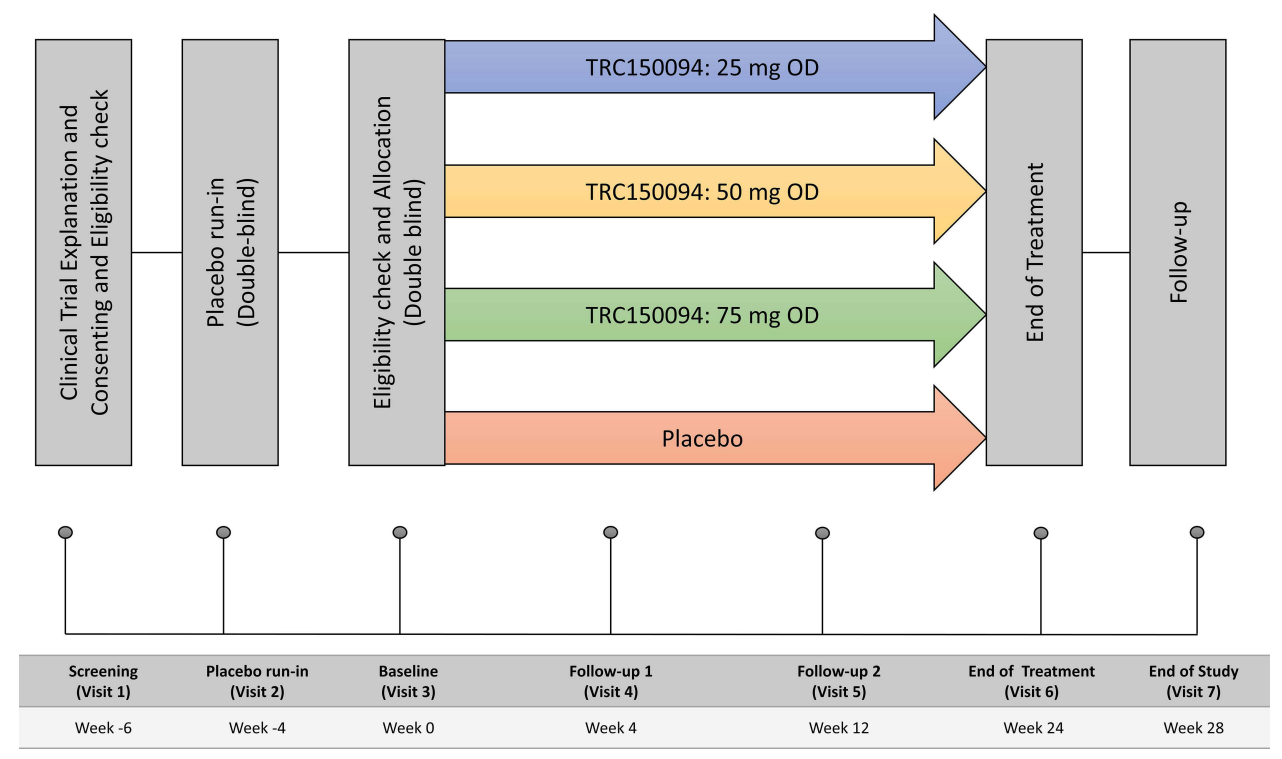

Figure I Study design of the TRCI50094 Phase II study. After obtaining informed consent on visit I, only subjects who satisfied the placebo run-in criteria at visit 3 were randomized in the ratio of I:I:I:I.5 to the TRCI50094 (25, 50, or $75 \mathrm{mg}$ ) or placebo till the end of the treatment (Visit 6); a follow-up was performed at the end of the study.

Abbreviation: OD, once daily.

\section{Study Population}

\section{Key Inclusion/Exclusion Criteria}

Eligible subjects were men and women, aged between 30 and 65 years, having body mass index (BMI) of $23-35 \mathrm{~kg} / \mathrm{m}^{2}$, waist circumference $\geq 90 \mathrm{~cm}$ (men) and $\geq 80 \mathrm{~cm}$ (women), fasting glucose of $\geq 126 \mathrm{mg} / \mathrm{dL}$ or glycated hemoglobin (HbAlc) of $\geq 6.4 \%$ or were stabilized on treatment with $\leq 2$ oral hypoglycemic agents (excluding alpha-glucosidase inhibitors). Additional inclusion criteria were apolipoprotein-B (apo-B) $\geq 100 \mathrm{mg} / \mathrm{dL}$, serum triglyceride (TG) $\geq 150 \mathrm{mg} /$ $\mathrm{dL}$, systolic blood pressure (SBP) $\geq 130 \mathrm{mmHg}$, and diastolic blood pressure (DBP) $\geq 85 \mathrm{mmHg}$ with/without antihypertensive treatment.

Key exclusion criteria were SBP/DBP $\geq 160 / 100 \mathrm{mmHg}$; receiving insulin therapy or anti-hyperlipidemic agents other than statins; fasting plasma glucose $(\mathrm{FPG})>200 \mathrm{mg} / \mathrm{dL}$ or $\mathrm{HbAlc}>8.5 \%$; serum $\mathrm{TG}>400 \mathrm{mg} / \mathrm{dL}$; low-density lipoprotein cholesterol (LDLc) $>300 \mathrm{mg} / \mathrm{dL}$ or medical history/clinical evidence of familial hyperlipidemic disorder; history of angina, myocardial infarction or stroke within 6 months of screening; alanine transaminase or aspartate transaminase $\geq$ three times the upper limit of normal; ethanol intake $>20 \mathrm{~mL} /$ day, estimated glomerular filtration rate $<30$ $\mathrm{mL} / \mathrm{min}$ as evaluated by Cockcroft-Gault method; thyroid dysfunction (thyroid-stimulating hormone $[\mathrm{TSH}]<0.3$ or $>5.0$ ) or euthyroid on thyroid medication or hormone-related obesity disorder; positive for HIV, Hepatitis B, Hepatitis C.

Eligible subjects were randomly assigned in a 1:1:1:1.5 ratio to receive either TRC150094 $(25,50$, or $75 \mathrm{mg})$ or placebo using a computer-generated list of random numbers. The randomization number of the subject will be decided by a central unblinded randomization center upon the request of the site/investigator. The investigational treatment was to be taken once daily, preferably in the morning under fasting conditions with water. TRC150094 was manufactured by/for Torrent Pharmaceuticals Ltd., India, as per Good Manufacturing Practice. Tablets were bulk supplied in high-density polyethylene bottles (30's count) containing desiccant and cotton, with an appropriate label.

\section{Procedure and Assessments Study Procedures}

Each eligible subject participated in the study for approximately 32-weeks, which consisted of a 4-week placebo-run-in phase, a 24-week double-blind, placebo-controlled treatment phase, and a 4-week of the follow-up phase. Participants who were found suitable as per the eligibility criteria were started on placebo for 4-weeks in the placebo run-in phase 
within 2-weeks of screening. During this period, compliance to the treatment was checked, dose adjustment of oral hypoglycemic agents and/or concomitant medication, if any, was carried out, and counseling for lifestyle modification was done. No modification in concomitant medication was allowed till the end of the treatment (visit 7) or follow-up visits after randomization unless there was an emergency.

After a 4-weeks of placebo run-in period, subjects visited the site at baseline, where randomization was performed. During the 24-week double-blind, placebo-controlled treatment phase, 24-hour ambulatory blood pressure (ABP), lipid, and glycemic parameters were assessed on baseline, 12-, and 24-week intervals. Also, a fat load test was performed to measure post-prandial lipid kinetics at baseline and 24-week in all randomized subjects. A standardized fat load and Vitamin A were administered after an overnight fast of at least 10 hours. Measurement of blood parameters, including retinyl palmitate (RP), triglycerides (TG), fasting glucose, and insulin, was done at baseline and week-24. In addition, hepatic fat measurement using magnetic resonance spectroscopy (MRS) and visceral and subcutaneous fat measurement using magnetic resonance imaging (MRI) was done in the subset of subjects at baseline and week-24. Safety was also assessed at every visit, including post-treatment follow-up visit at week-28.

The primary efficacy outcomes were to compare mean change in MAP, fasting plasma glucose (FPG), and insulin, and apo-B from baseline to week-24 between active treatment groups vs placebo. Secondary efficacy outcomes were comparisons of TRC150094 groups versus placebo for change in non-high-density lipoprotein cholesterol (nHDLc), apoB/apo-A1 ratio, hepatic fat, and visceral fat (in the subset). Additional efficacy outcomes were change in body weight, BMI, sagittal abdominal diameter, waist circumference, systolic and diastolic BP (overall, awake and asleep), Homeostasis Model Assessment Insulin Resistance (HOMA-IR), HbA1c, serum TG, total cholesterol (TC), LDLc, high-density lipoprotein -cholesterol (HDLc), small dense low-density lipoprotein cholesterol (sdLDLc), subcutaneous fat (in the subset), the area under curve 0 to 6 hours $\left(\mathrm{AUC}_{0-6 \mathrm{~h}}\right)$ of $\log$-transformed insulin and glucose clearance of fat load test.

Safety was evaluated by adverse event (AEs) monitoring, physical examination, vital signs, electrocardiogram (ECG), and laboratory variables, including hematology, biochemistry, and urine analysis. All the serious adverse events were reported to the IRB as well as the DCGI. An independent drug safety monitoring board evaluated all safety data and the study's progress. All the laboratory analyses were performed using standard methods at Super Religare Laboratories Ltd (Mumbai, India), accredited by the National Accreditation Board for Testing and Calibration Laboratory.

Prior to the analysis, the subjects were withdrawn from the study if they did not fulfill any inclusion/exclusion criteria apart from protocol waivers or modifications in concomitant medications and its dose beyond those allowed as per the protocol that would impact study data, or if the investigational product compliance was $<80 \%$. Protocol waivers were granted only for parameters (Apo B, FPG, TSH) where definite cut-off values of eligibility were unknown due to absence of reliable data in the Indian population.

\section{Sample Size and Statistical Analysis}

The calculation was based on primary endpoints between treatment groups. However, the study was not powered for all the tests since no information was available on the expected effect size of the medication. Trends for apoB levels from multiple ascending dose study suggested effect size in the range of 10-15\% after 4-weeks treatment with TRC150094 against placebo. ${ }^{10}$ Thus, to evaluate efficacy at $80 \%$ power, significance level (alpha) of 0.05 , with the assumption of the mean (SD) of 100 (20) and difference of 10\%, 42 subjects' data need to be included for analysis while assuming onesided hypothesis and maintaining the ratio of 1:1.5 (each dose: placebo). With an estimated dropout of $15 \%, 50$ subjects were planned to be randomized in each treatment arm and 75 subjects randomized to the placebo arm. Primary, secondary, and additional efficacy analyses were performed on the modified intention to treat (mITT) and per protocol populations. Subgroup and exploratory analyses were performed on the mITT population.

\section{Primary, Secondary, and Exploratory Analysis}

The efficacy variables were analyzed using one-way analysis of variance (ANOVA) to identify the statistical difference between four groups using last observation carried forward for missing data and after checking assumptions for normality and homogeneity of variance. The pair-wise comparison was carried out between the treatment groups and placebo using 
Tukey's test. Kruskal-Wallis test was performed for non-normally distributed data. This was followed by post hoc analysis using the Dwass, Steel, Critchlow-Fligner (DSCF) multiple comparison procedure performed at a 5\% level of significance. For MAP, a comparison between active treatment group and placebo for change from baseline to week-24 with or without adjustment for traditional risk factors (age, gender, BMI) was analyzed using ANCOVA with baseline as covariate. A post hoc Tukey's test was performed at a 5\% level of significance. For individual comparisons, p-value $<0.05$ was considered statistically significant. Statistical analyses were performed using the SAS (Statistical Analysis Software 9.4, SAS Institute Inc., Cary, North Carolina, USA).

\section{Results}

\section{Study Population}

A total of 225 participants were randomized to receive TRC150094 $(25,50$, or $75 \mathrm{mg})$ or placebo once daily for 24 weeks. Of these, 190 subjects completed the treatment phase up to week-24. The disposition of subjects in the study is presented in Figure 2. The mITT population consisted of 205 subjects. Baseline demographics and disease characteristics were similar among different study groups (Table 2). As the study population comprises subjects with T2D, dyslipidemia, and hypertension, the background therapy included oral antidiabetics, lipid-lowering agents, and antihypertensives. The most common oral antidiabetic drug used by the subjects was metformin (97\%), followed by sulphonylurea (70\%). Lipid modifying agents were used by $47 \%$ of subjects, while among antihypertensives, angiotensin-converting enzyme inhibitor/angiotensin receptor blockers (35\%) were commonly used. (Table 2) The distribution of concomitant medications was similar between different treatment groups.

\section{Efficacy}

\section{Glycemic Parameters}

FPG and fasting insulin were the primary efficacy endpoints in the study.

\section{FPG}

Treatment with TRC150094 showed a reduction in FPG up to $50 \mathrm{mg}$ dose, which was statistically significant $(\mathrm{p}<0.05)$ at

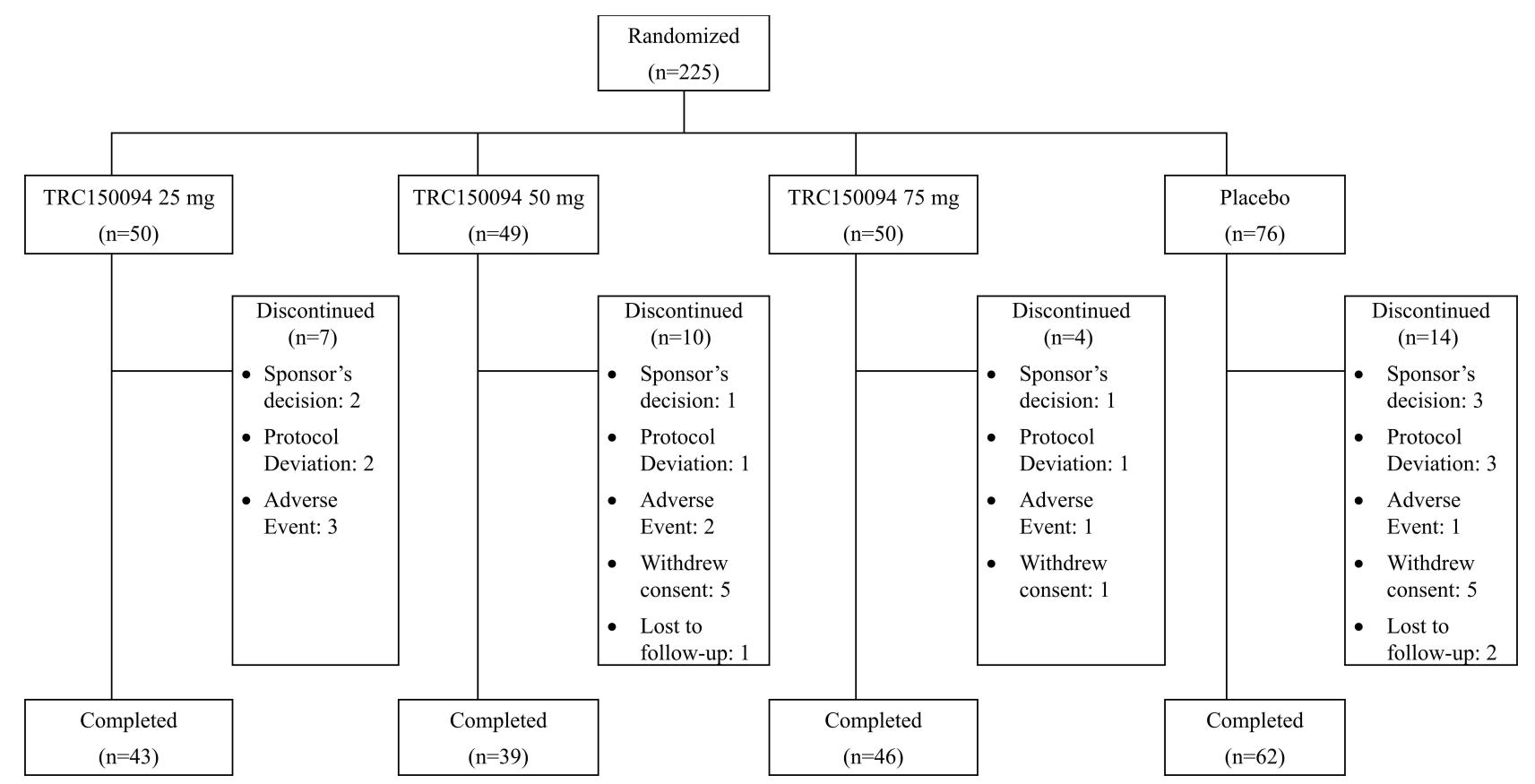

Figure 2 Subject disposition. 
Table 2 Demographics and Baseline Characteristics

\begin{tabular}{|c|c|c|c|c|}
\hline \multirow[t]{2}{*}{ Parameter, Units } & \multicolumn{3}{|c|}{ TRCI50094 } & \multirow[t]{2}{*}{ Placebo $(n=70)^{*}$} \\
\hline & $25 \mathrm{mg}(\mathrm{n}=47)^{*}$ & $50 \mathrm{mg}(\mathrm{n}=42)^{*}$ & $75 \mathrm{mg}(\mathrm{n}=46)^{*}$ & \\
\hline Age, years & $50.10(7.1)$ & $50.39(8.2)$ & $50.78(7.7)$ & 50.51 (7.9) \\
\hline Gender (Male), n (\%) & $24(48.0)$ & $27(55.1)$ & $27(54.0)$ & $42(55.3)$ \\
\hline Body weight, kg & $71.07(10.3)$ & $72.50(8.1)$ & $73.48(11.3)$ & $73.42(10.1)$ \\
\hline HbAlc, \% & $7.06(1.0)$ & $6.89(0.8)$ & $7.25(1.1)$ & $6.96(1.0)$ \\
\hline FPG, $\mathbf{m g} / \mathrm{dL}$ & $137.62(45.4)$ & $131.26(30.4)$ & $135.00(35.2)$ & $122.90(29.5)$ \\
\hline Fasting Insulin, mU/L & $19.45(17.7)$ & $23.02(31.6)$ & $21.87(23.8)$ & $19.59(20.5)$ \\
\hline HOMA-IR & $7.69(13.4)$ & $7.57(9.5)$ & $7.56(8.5)$ & $6.14(7.3)$ \\
\hline MAP, mmHg & $89.65(10.3)$ & $89.35(9.4)$ & $92.30(9.6)$ & $89.64(10.7)$ \\
\hline SBP, mmHg & $122.83(14.9)$ & $123.66(13.7)$ & $126.87(13.4)$ & $124.26(14.8)$ \\
\hline DBP, mmHg & $73.06(8.6)$ & $72.20(7.9)$ & $75.02(8.3)$ & $72.33(9.7)$ \\
\hline ApoB, g/L & $1.05(0.3)$ & $1.07(0.2)$ & I.0I (0.2) & $1.03(0.3)$ \\
\hline T. Cholesterol, mg/dL & $73.06(8.6)$ & $72.20(7.9)$ & $75.02(8.3)$ & $72.33(9.7)$ \\
\hline nHDLc, mg/dL & I54.09 (47.7) & 157.69 (37.9) & I 48.76 (36.4) & $152.76(37.3)$ \\
\hline \multicolumn{5}{|c|}{ Concomitant Medications,\% } \\
\hline Metformin & 94 & 98 & 94 & 100 \\
\hline Sulfonylurea & 80 & 59 & 62 & 70 \\
\hline Lipid modifying agents & 46 & 53 & 34 & 53 \\
\hline ACEi/ARB & 32 & 37 & 34 & 38 \\
\hline CCB & 24 & 20 & 34 & 21 \\
\hline Beta blockers & 8 & 12 & 22 & 13 \\
\hline
\end{tabular}

Note: *Data presented as mean (SD).

Abbreviations: ACEi, angiotensin converting enzyme inhibitor; Apo B, apolipoprotein B; ARB, angiotensin receptor blocker; CCB, calcium channel blocker; DBP, diastolic blood pressure; FPG, fasting plasma glucose; HbAlc, glycated hemoglobin; nHDLc, non-high density lipoprotein-cholesterol; HOMA-IR, homeostasis model assessment insulin resistance; SBP, systolic blood pressure; SD, standard deviation.

both $25 \mathrm{mg}$ and $50 \mathrm{mg}$ doses as compared to placebo. Placebo-subtracted change from baseline at the end of treatment ranged between -13.85 and $-21.74 \mathrm{mg} / \mathrm{dL}$ (Figure $3 \mathrm{~A}$ ).

\section{Fasting Insulin}

An increase in fasting insulin levels in subjects on $\mathrm{SoC}$ receiving placebo was observed over the duration of the study. In the groups treated with TRC150094, a placebo-subtracted reduction of 2.7 to $6.0 \mathrm{mU} / \mathrm{L}$ was observed in fasting insulin levels at week-24 (Figure 3B). Reducing trends of fasting insulin levels were noted in a dose-dependent manner, though it was not statistically significant $(\mathrm{p}>0.05)$.

\section{HOMA-IR}

A reduction in placebo-subtracted HOMA-IR score $>2$ was observed across all TRC150094 treated groups (Figure 3C), which was not statistically significant $(\mathrm{p}>0.05)$. 


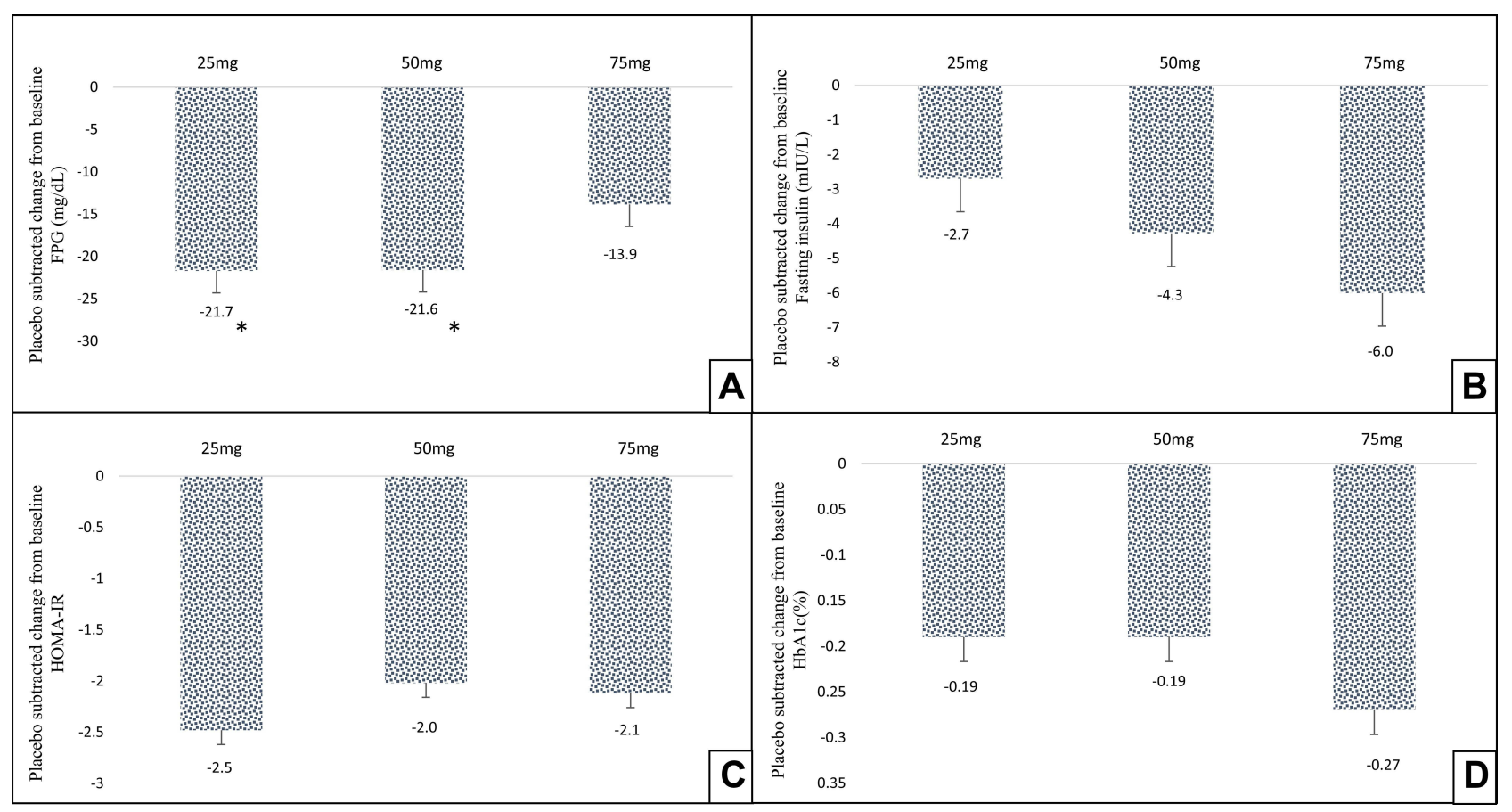

Figure 3 Effect of TRCI50094 treatment on glycemic parameters, mean placebo-subtracted change from baseline in TRCI50094 (25, 50, 75 mg) added to SoC at 24-week for (A) FPG (mg/dL), (B) fasting insulin, (C) HOMA-IR, (D) HbAlc. ${ }^{*}<0.05$ change from baseline compared to placebo (Kruskal-Wallis test followed by pairwise comparison using DSCF procedure).

Abbreviations: DSCF, Dwass-Steel-Critchlow-Fligner; FPG, fasting plasma glucose; HbAlc, glycated hemoglobin; HOMA-IR, homeostasis model assessment insulin resistance; SoC, standard of care.

\section{HBAIc}

At week-24, a small but consistent placebo-subtracted change from baseline was seen across all dose levels (Figure 3D).

\section{$\mathrm{AUC}_{0-6 \mathrm{~h}}$ of Fasting Insulin and Glucose}

In the fat load test, the placebo group showed a deterioration of insulin sensitivity, as evident by a reduction in $\mathrm{AUC}_{0-6 \mathrm{~h}}$ of insulin and a consequent increase in $\mathrm{AUC}_{0-6 \mathrm{~h}}$ of glucose. At $25 \mathrm{mg}$ dose of TRC150094, the mean $\mathrm{AUC}_{0-6 \mathrm{~h}}$ of insulin after fat load test increased from baseline, though not statistically significant. It was accompanied by a statistically significant reduction in mean $\mathrm{AUC}_{0-6 \mathrm{~h}}$ of glucose as compared to placebo $(\mathrm{p}<0.05)$. At $50 \mathrm{mg}$, a similar trend was observed, ie, an increase in $\mathrm{AUC}_{0-6 \mathrm{~h}}$ of insulin and a corresponding reduction in $\mathrm{AUC}_{0-6 \mathrm{~h}}$ of glucose, though less in magnitude compared to the $25 \mathrm{mg}$ dose. At $75 \mathrm{mg}$ dose, the $\mathrm{AUC}_{0-6 \mathrm{~h}}$ of insulin output did not increase in response to fat load, and $\mathrm{AUC}_{0-6 \mathrm{~h}}$ of glucose showed less reduction compared to other treatment arms (Table 3).

\section{Blood Pressure}

MAP was part of the primary efficacy endpoint of the study. Placebo-subtracted MAP change at 24 weeks was -3.1 , -0.31 , and $-4.2 \mathrm{mmHg}$ for 25,50 , and $75 \mathrm{mg}$ dose groups, respectively. MAP reduction was statistically significant $(\mathrm{p}<$ 0.05 ) for the $25 \mathrm{mg}$ and $75 \mathrm{mg}$ dose groups. Similarly, there was also a reduction in the range between 3.2 and $7.5 \mathrm{mmHg}$

Table 3 Effect of TRC150094 Treatment on Post-Prandial Glucose (AUC ${ }_{0-6 h r}$ Glucose) and Insulin (AUC $0-6 \mathrm{hr}$ Insulin)

\begin{tabular}{|l|c|c|c|}
\hline \multirow{2}{*}{ Parameters } & \multicolumn{2}{|c|}{ Placebo-Subtracted Mean Change from Baseline to Week-24 } \\
\cline { 2 - 4 } & $\mathbf{2 5 m g ~ ( n = 4 7 )}$ & $\mathbf{5 0 m g ~ ( n = 4 2 )}$ & $\mathbf{7 5 m g ~ ( n = 4 6 )}$ \\
\hline AUC Glucose & $-184.928^{*}$ & -135.30 & -128.73 \\
\hline AUC Insulin & 36.26 & 38.42 & -20.21 \\
\hline
\end{tabular}

Notes: $* \mathrm{P}<0.05$ compared to placebo (Kruskal-Wallis test followed by pairwise comparison using DSCF procedure). 
across different dose levels in nighttime MAP, which was statistically significant at $50 \mathrm{mg}$ dose compared to placebo. Daytime awake MAP showed a placebo-subtracted change in the range of 0.81 to -4.98 with no statistically significant reduction compared to placebo at any dose (Figure 4). A clinically significant placebo-subtracted reduction from baseline was observed at week-24 for $75 \mathrm{mg}$ dose in the $24 \mathrm{hr}$. $(-5.4 \mathrm{mmHg})$ and awake SBP $(-6.1 \mathrm{mmHg})$. There was also a statistically significant placebo-subtracted reduction in DBP, overall and awake at $25 \mathrm{mg}(-3.8$ and $-4.3 \mathrm{mmHg}$, respectively) and $75 \mathrm{mg}(-3.6$ and $-4.5 \mathrm{mmHg}$, respectively).

\section{Lipid Parameters}

Apo B was part of the primary efficacy endpoint for the study.

\section{Apo B}

There was not much change over time in subjects on $\mathrm{SoC}$ receiving placebo as well as those on treatment with TRC150094. The changeover baseline ranged from 0.02 to $-0.05 \mathrm{~g} / \mathrm{dL}$.

\section{Other Atherogenic Lipid Parameters}

In the subjects on TRC150094, $25 \mathrm{mg}$ was not adequate to cause a reduction in atherogenic lipid fractions. However, there was a consistent trends in reduction for all the atherogenic lipid fractions, including TC, nHDLc, LDLc, sdLDLc at

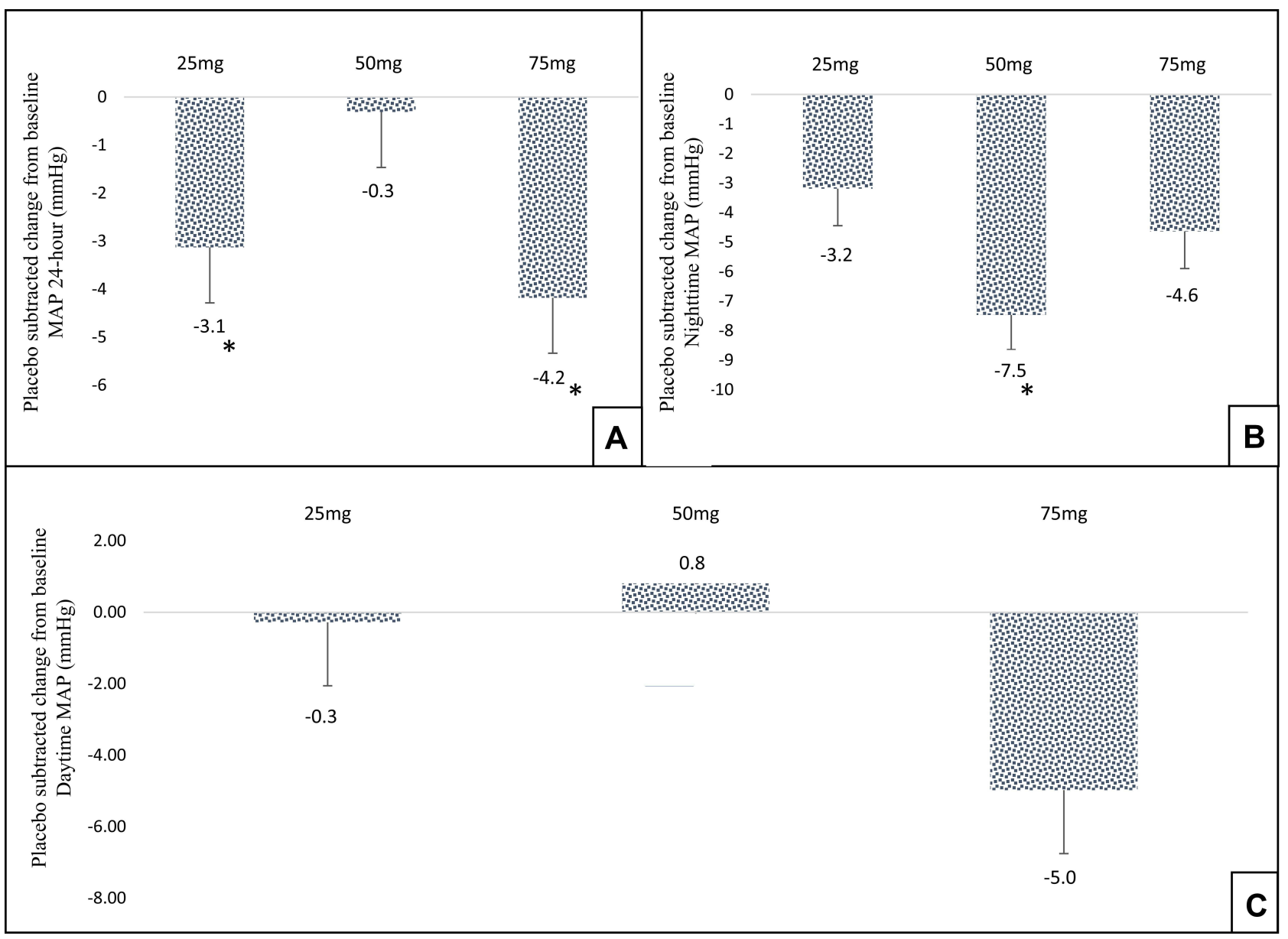

Figure 4 Effect of TRCI50094 treatment on blood pressure, (A) mean placebo-subtracted change from baseline in TRCI50094 (25, 50, 75 mg) added to SoC for 24-hour MAP ( $\mathrm{mmHg}$ ) at 24-week. (B) Mean placebo-subtracted change from baseline in TRCI50094 (25, 50, $75 \mathrm{mg})$ added to SoC for nighttime MAP (mmHg) at 24-week. (C) Mean placebo-subtracted change from baseline in TRCI 50094 (25, 50, $75 \mathrm{mg})$ added to SoC for daytime MAP (mmHg) at $24-$ week. *p<0.05 change from baseline compared to placebo using ANCOVA and pairwise comparison using Tukey's test.

Abbreviations: MAP, mean arterial pressure; SoC, standard of care. 


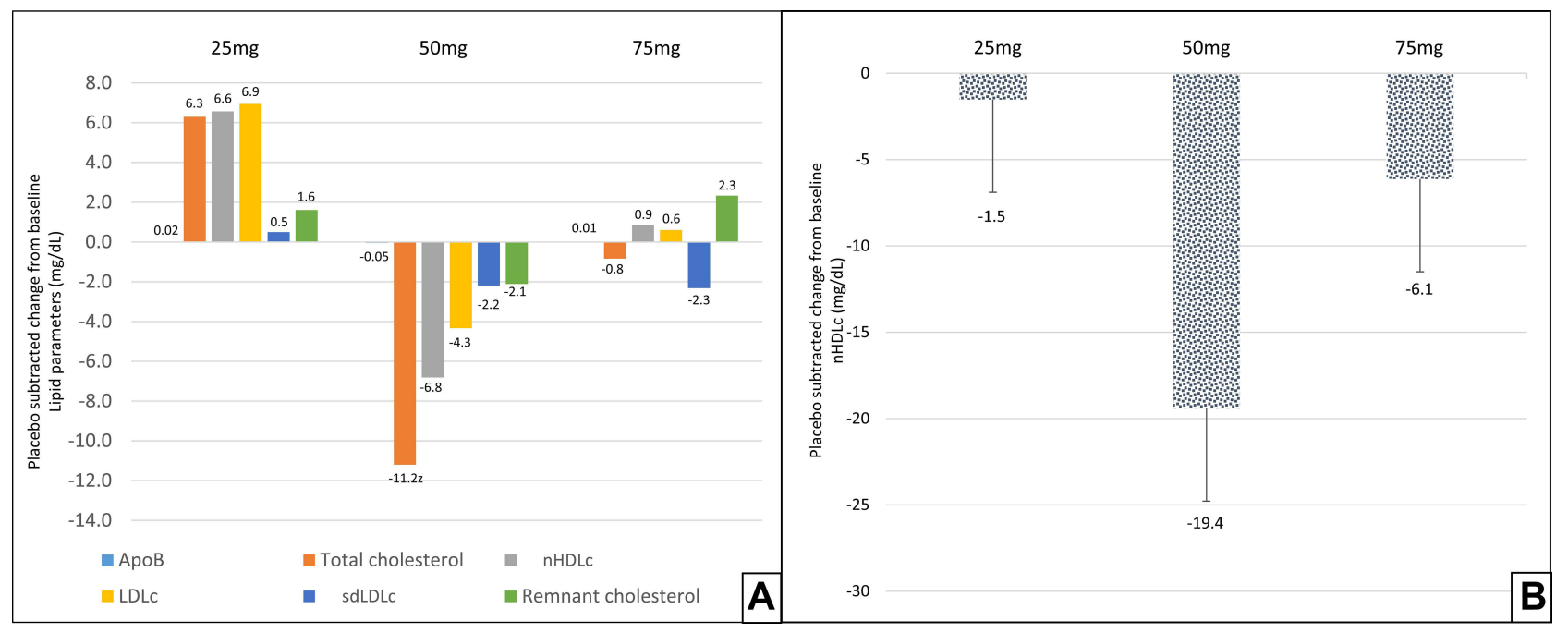

Figure 5 Effect of TRCI50094 on lipid parameters, (A) mean placebo-subtracted change from baseline in TRCI50094 (25, 50,75 mg) added to SoC for various atherogenic lipid fractions 24-week, double-blind treatment period. (B) Mean placebo-subtracted change from baseline in TRCI50094 (25, $50,75 \mathrm{mg})$ in subjects not receiving statin therapy for nHDLc at 24-week.

Abbreviations: Apo B, apolipoprotein B; LDLc, low density lipoprotein-cholesterol; nHDLc, non-high density lipoprotein-cholesterol; sdLDLc, small dense low density lipoprotein-cholesterol, SoC, standard of care.

$50 \mathrm{mg}$ dose (Figure 5A). At $75 \mathrm{mg}$, changes in lipid fractions were not consistent across different fractions and showed higher variability in response.

In the study, $47 \%$ of the subjects were receiving lipid-modifying therapy (statins), and the remaining were not receiving any statin therapy (Table 2). TRC150094 at $50 \mathrm{mg}$ in congruence with the overall effect on lipid fractions showed a trend in reduction of nHDLc levels (Figure 5B).

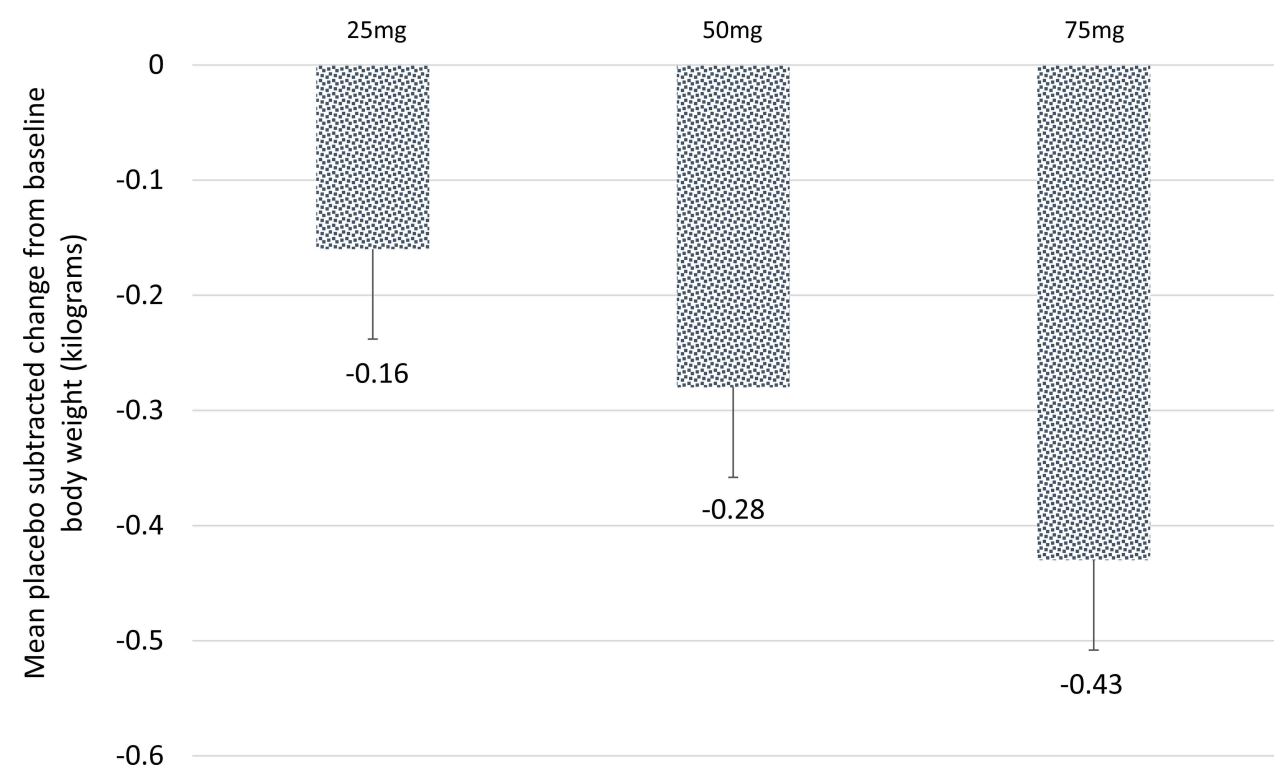

Figure 6 Effect of TRCI50094 on body weight. Mean placebo-subtracted change from baseline in TRCI50094 (25, 50, 75 mg) added to SoC at 24-week. 


\section{Other Exploratory Parameters \\ Weight}

There was a marginal reduction in weight in all treatment groups. Treatment with TRC150094 was weight neutral, as shown in Figure 6.

TRC150094 treatment did not result in meaningful changes in other parameters, including hepatic, visceral, and subcutaneous fat, BMI, sagittal abdominal diameter, waist circumference, apoB/apoA1, and retinyl palmitate. The effect of TRC150094 on exploratory parameters are shown in more details in Table 4.

\section{Safety and Tolerability}

Generally, AEs were reported at similar frequencies across all groups. No deaths occurred in the study. One serious TEAE of chronic lymphocytic leukemia was reported in 1 subject in TRC150094 $50 \mathrm{mg}$ group. The SAE was considered moderate in severity and not related to the study drug. Overall, there were $10(5.2 \%)$ TEAE reported in 8 (3.6\%) subjects, which led to study drug discontinuation. However, there was no dose-response relationship seen, and frequency was similar across all groups.

Approximately 44\% (99/225) of subjects had at least one TEAE after randomization. The TEAEs that occurred after randomization in the majority of subjects (33.8\% [76/225]) were not related to the study drugs. The TEAEs in $12.9 \%$ (29/ $225)$ and $1.8 \%$ (4/225) of subjects were probably and possibly related to the study drugs, respectively. In $2.7 \%(6 / 225)$ of subjects, the TEAEs were unlikely to be related to the study drug.

The most common TEAEs (frequency of $>3 \%$ in each treatment group) reported were similar between all the treatment groups. In those where the frequency of TEAE in the treatment group was greater than the placebo group, no dose relationship was evident (Table 5).

\section{Discussion}

This study examined the effects of a novel mitochondrial modulator, TRC150094, in CMBCD subjects with co-existing diabetes, dyslipidemia, and hypertension and receiving standard of care. Compared to placebo, TRC150094 treatment showed improvement in glycemic control, atherogenic lipid fractions, and blood pressure.

Improvement in glycemic control was evident by a reduction in plasma glucose accompanied by a reducing trend of fasting insulin along with improving trends of HOMA-IR, indicating an improvement in insulin sensitivity. Improvement in insulin reserve was also reflected in the improvement in the insulin output when challenged and consequent control of post-challenge glucose exposure. A trend in reduction of $\mathrm{HbA} 1 \mathrm{c}$ levels also reflected the outcome of better post-prandial control. Although not significant statistically across different parameters, the changes were dose-related up to the $50 \mathrm{mg}$ dose. Beyond $50 \mathrm{mg}$, the effect seemed to plateau with less effect on fasting and post-prandial glucose control and lower insulin reserve. Even though the HbA1c improvement achieved was similar; however, it showed variability and outliers in response at the highest dose. This was further confirmed by a reduction in AUC glucose at 25 and $50 \mathrm{mg}$ accompanied by an increase in AUC insulin. However, this effect was not evident at the $75 \mathrm{mg}$ dose. The modest reduction in HbAlc in the study is not surprising, considering the mildly deranged baseline HbAlc values of between $6.96 \%$ and $7.25 \%$. A trend towards a more pronounced reduction was noted in those who had higher baseline HbAlc. These findings confirm a previous study by van der Valk et al, which reported a trend towards improvement in insulin sensitivity in subjects with dyslipidemia with mild metabolic derangement treated with TRC150094 $50 \mathrm{mg}$ for four weeks ${ }^{11}$ and extended it to subjects with obvious insulin resistance at baseline.

Congruous with effect on glycemic parameters was an effect on the lipid profile, with a lack of effect at $25 \mathrm{mg}$ but consistent reducing trends of all fractions at $50 \mathrm{mg}$. Similarly, the effect on lipid fractions at $75 \mathrm{mg}$ was variable and not consistent.

Overall, TRC150094 treatment resulted in a significant decrease in 24-hour MAP and a clinically meaningful reduction in nighttime (sleep) MAP. Improvement in nighttime MAP is associated with better outcomes, including allcause and cardiovascular mortality, coronary heart disease, and stroke in hypertensive patients. ${ }^{12}$ This effect was observed at 25 and $75 \mathrm{mg}$ doses. At $50 \mathrm{mg}$, though, few subjects whose daytime MAP was unusually high confounded the overall response. On further stratification, subjects with MAP values $\geq 100 \mathrm{mmHg}$ showed a slightly greater reduction 
Table 4 Effect of TRCI50094 Treatment on Exploratory Parameters

\begin{tabular}{|c|c|c|c|c|}
\hline \multirow[t]{2}{*}{ Parameter } & \multicolumn{3}{|c|}{ TRCI50094 } & \multirow[t]{2}{*}{ Placebo } \\
\hline & $25 \mathrm{mg}$ & $50 \mathrm{mg}$ & $75 \mathrm{mg}$ & \\
\hline \multicolumn{5}{|l|}{ Hepatic Fat (\%) } \\
\hline Mean baseline hepatic fat* & $6.10(2.79)$ & $7.21(2.78)$ & $7.62(4.74)$ & $9.00(5.31)$ \\
\hline Mean change from baseline to week-24* & $0.79(3.08)$ & $0.92(5.78)$ & $0.35(1.32)$ & $1.06(3.43)$ \\
\hline Placebo-subtracted mean change from baseline to week- 24 & -0.27 & -0.14 & $-0.7 \mathrm{I}$ & \\
\hline \multicolumn{5}{|l|}{ Visceral Fat $\left(\mathrm{cm}^{2}\right)$} \\
\hline Mean baseline log visceral fat* & $4.91(0.49)$ & $4.92(0.35)$ & $4.89(0.39)$ & $4.80(0.33)$ \\
\hline Mean change from baseline to week-24* & $-0.01(0.34)$ & $0.10(0.23)$ & $-0.06(0.24)$ & $-0.01(0.29)$ \\
\hline Placebo-subtracted mean change from baseline to week- 24 & 0 & 0.11 & -0.05 & \\
\hline \multicolumn{5}{|l|}{ Log subcutaneous fat $\left(\mathrm{cm}^{2}\right)$} \\
\hline Baseline log subcutaneous fat* & $5.55(0.27)$ & $5.58(0.31)$ & $5.58(0.36)$ & $5.63(0.37)$ \\
\hline Mean change from baseline to week-24* & $-0.02(0.09)$ & $0.05(0.28)$ & $-0.02(0.13)$ & $0.02(0.14)$ \\
\hline Placebo-subtracted mean change from baseline to week- 24 & -0.04 & 0.03 & -0.04 & \\
\hline \multicolumn{5}{|l|}{ BMI $\left(\mathrm{kg} / \mathrm{m}^{2}\right)$} \\
\hline Mean baseline Body Mass Index* & $28.13(3.18)$ & $28.33(2.67)$ & $28.79(3.24)$ & $28.41(3.06)$ \\
\hline Mean change from baseline to week-24* & $-0.10(0.93)$ & $-0.16(0.52)$ & $-0.21(0.53)$ & $-0.05(0.45)$ \\
\hline Placebo-subtracted mean change from baseline to week-24 & -0.05 & -0.11 & -0.16 & \\
\hline \multicolumn{5}{|l|}{ Sagittal Abdominal Diameter $(\mathrm{cm})$} \\
\hline Mean baseline Sagittal abdominal diameter* & $23.79(2.12)$ & $23.66(1.88)$ & $23.85(2.10)$ & $23.75(2.05)$ \\
\hline Mean change from baseline to week-24* & $-0.28(0.67)$ & $-0.27(1.06)$ & $-0.09(0.42)$ & $-0.20(1.20)$ \\
\hline Placebo-subtracted mean change from baseline to week-24 & -0.08 & -0.07 & 0.11 & \\
\hline \multicolumn{5}{|l|}{ Waist Circumference (cm) } \\
\hline Mean baseline waist circumference* & $97.99(7.83)$ & $98.68(6.92)$ & $97.41(7.42)$ & $97.15(7.49)$ \\
\hline Mean change from baseline to week-24* & $-0.05(1.54)$ & $-0.64(1.97)$ & $-0.61(2.06)$ & $-0.36(1.54)$ \\
\hline Placebo-subtracted mean change from baseline to week- 24 & 0.31 & -0.28 & -0.25 & \\
\hline \multicolumn{5}{|l|}{ Apo-B/Apo-AI ratio } \\
\hline Mean baseline Apo-B/Apo-AI ratio* & $0.81(0.22)$ & $0.83(0.18)$ & $0.80(0.19)$ & $0.85(0.24)$ \\
\hline Mean change from baseline to week-24* & $-0.00(0.20)$ & $-0.04(0.22)$ & $-0.02(0.18)$ & $-0.05(0.17)$ \\
\hline Placebo-subtracted mean change from baseline to week-24 & 0.05 & 0.01 & 0.03 & \\
\hline \multicolumn{5}{|l|}{ Retinyl Palmitate AUC (mg*hr/dL) } \\
\hline Mean baseline retinyl palmitate AUC* & $11.70(9.09)$ & $10.79(6.44)$ & $11.79(9.00)$ & $11.98(8.66)$ \\
\hline Mean change from baseline to week-24* & $2.48(8.10)$ & $1.54(11.36)$ & $-0.50(10.94)$ & $1.60(9.36)$ \\
\hline Placebo-subtracted mean change from baseline to week-24 & 0.88 & -0.06 & -2.1 & \\
\hline
\end{tabular}

Note: *Data presented as mean (SD). 
Table 5 Summary of Most Common (Frequency >3\%) Treatment-Emergent Adverse Events (TEAE) in the Different Treatment Groups for TRCI50094 (25, 50, and $75 \mathrm{mg})$ and Placebo

\begin{tabular}{|c|c|c|c|c|}
\hline \multirow[t]{2}{*}{ Events } & \multicolumn{3}{|c|}{ TRCI50094 } & \multirow[t]{2}{*}{ Placebo $(n=76) N(\%)$} \\
\hline & $25 \mathrm{mg}(\mathrm{n}=50) \mathrm{N}(\%)$ & 50 mg (n=49) N (\%) & 75 mg (n=50) N (\%) & \\
\hline Increased corticotrophin & $5(10)$ & $4(8.2)$ & $5(10)$ & $9(11.8)$ \\
\hline Hyperglycemia & $5(10)$ & $5(10.2)$ & $2(4.0)$ & $6(7.9)$ \\
\hline Increased GGT & $2(4)$ & $3(6.1)$ & I (2.0) & 0 \\
\hline Blood TG Increased & $2(4)$ & I (2.0) & 0 & I (I.3) \\
\hline Increased Liver Enzyme & $2(4)$ & 0 & 0 & 0 \\
\hline Increased Troponin & $2(4)$ & 0 & 0 & 0 \\
\hline Dyslipidemia & $2(4)$ & $3(6.1)$ & $2(4.0)$ & I (I.3) \\
\hline Hyperkalaemia & $2(4)$ & 0 & 0 & 0 \\
\hline Constipation & $2(4)$ & 0 & 0 & $\mathrm{I}(\mathrm{l} .3)$ \\
\hline Hypothyroidism & $2(4)$ & I (2.0) & $2(4.0)$ & $3(3.9)$ \\
\hline Increased TSH & 0 & $2(4.1)$ & 0 & $\mathrm{I}(\mathrm{I} .3)$ \\
\hline UTI & 0 & $2(4.1)$ & I (2.0) & $2(2.6)$ \\
\hline Dizziness & I (2.0) & $2(4.1)$ & 0 & $2(2.6)$ \\
\hline Decreased cortisol & 0 & 0 & $2(4.0)$ & $3(3.9)$ \\
\hline URTI & I (2.0) & I (2.0) & 0 & $3(3.9)$ \\
\hline
\end{tabular}

Abbreviations: GGT, gamma-glutamyl transaminase; TG, triglyceride; TSH, thyrotropin stimulating hormone; URTI, upper respiratory tract infection; UTI, urinary tract infection.

of between 2.2 and $10 \mathrm{mmHg}$. With an improvement in insulin sensitivity, there was also an improvement in endothelial function reflected by a reduction in MAP, SBP, and DBP. While it is known that insulin resistance may only partly explain the impaired endothelial function, there are other possible factors such as hyperglycemia, hyperlipidemia, cytokines that selectively impair the phosphatidylinositol 3-kinase (PI3K/Akt/eNOS) pathway, explaining variability in the response of MAP.

TRC150094 was found to be very safe over the treatment period of 24 weeks. The incidence of AEs was similar in all the treatment groups [TRC150094 $25 \mathrm{mg}(28 \%), 50 \mathrm{mg}$ (20.4\%), $75 \mathrm{mg}(16 \%)$ and placebo (19.7\%)]. There were no treatment-related incidences of hypoglycemia. Overall, there were no safety concerns with TRC150094.

The underpinnings of metabolic inflexibility manifesting as reduced skeletal muscle glucose disposal rate, impaired suppression of hepatic gluconeogenesis, and adipose tissue lipolysis due to insulin resistance and the beginning of a slightly compromised pancreatic beta-cell reserve were seen in the population in this study. ${ }^{3}$ A consequence of insulin resistance is also upregulation of the pro-hypertensive pathways. Consistent with the mechanism of action of TRC150094, a first-in-class mitochondrial modulator, showed an improvement in insulin resistance and associated reduction in fasting and post-prandial glucose, atherogenic lipid fractions, and blood pressure in subjects treated for 24 weeks.

While lifestyle modification and metformin are the cornerstone of the initial management of type 2 diabetes mellitus and an array of other targets for second and third-line treatments are available, there is no single agent that also addresses the commonly co-existing co-morbid conditions of dyslipidemia and hypertension. Metformin's action on mitochondria at the clinically relevant drug concentrations is not clear and still arguable. ${ }^{13}$ Greater oxidation of fat resulting in insulin resistance with metformin is possibly mediated through its modulatory action on adenosine monophosphate kinase 
(AMPK) with an indirect inhibition of electron transport chain complex-I. ${ }^{14}$ Similarly, imeglimin, derived from metformin, does not directly inhibit mitochondrial electron transport complex or forward respiratory flux but possibly indirectly affects it through a mechanism that remains to be explored in more detail. ${ }^{11}$ While the benefits of both are limited to improvement in glycemic control primarily driven by the effect on hepatic gluconeogenesis. Other agents like dipeptidyl-peptidase-4 inhibitors and sodium-glucose co-transporter-2 inhibition translate into a clinical benefit in terms of glycemic control and its associated cardiac complications by virtue of their hemodynamic actions. However, metabolic modulation has little or no direct hemodynamic, inotropic, or chronotropic effect but improves energy efficiency/ expenditure and restores metabolic flexibility and its associated metabolic defects.

This study has some limitations. First, subjects had a modestly deranged baseline, reducing the scope for demonstrating further improvement. Amongst those subjects who had a more deranged baseline, response to treatment was better; however, numbers in these subgroups were small. Second, ABP monitoring is not a common practice in India. Despite counseling by the investigators, there was noise during awake daytime recording in some subjects, which could have confounded the 24-hour recording. Third, the study had a small number of subjects per group, and the efficacy, safety, and tolerability need to be evaluated in a larger study. Considering the mechanism of action, intermittent treatment could also be an option.

Nevertheless, despite background therapy for glycemic control with 1-2 oral anti-diabetics, dyslipidemia with statins, and hypertension with at least one antihypertensive drug, TRC150094 treatment in this study resulted in trends towards an improvement in all three parameters. Improvement was seen in glycemic and blood pressure control at $25 \mathrm{mg}$, as well as in glycemic and lipid control at $50 \mathrm{mg}$. The response with $50 \mathrm{mg}$ also indicated a potential benefit in controlling blood pressure if studied in a larger cohort. At a higher dose of $75 \mathrm{mg}$, there was a variable and inconsistent response on several of the parameters examined for glycaemic and lipid control. One can postulate that upregulation of lipolytic and gluconeogenetic pathways beyond a threshold is leading to increased circulating substrates at the higher dose. Nonetheless, the absence of any safety signals at all doses during the study was encouraging. This study suggests that TRC150094, by its mitochondrial modulatory action, can provide therapeutic benefit if studied within in a range of 25-50 $\mathrm{mg}$ in a larger patient population having a more deranged baseline.

The basis of CMBCD is a common thread linking IR to dysglycemia and dyslipidemia, which intersects with hypertension and progresses to downstream CVD. TRC150094, while being safe and well tolerated, displays a trend towards improvements across the spectrum of cardio-metabolic risk factors when added to the standard of care. Based on this study, further clinical evaluation of TRC150094 is worth exploring in a phase-3 clinical trial in the CMBCD population with co-existing type 2 diabetes mellitus, dyslipidemia, and hypertension.

\section{Conclusion}

In this study, TRC150094 treatment in the dose range of 25 to $50 \mathrm{mg}$ was safe and well tolerated and showed improvement in various components of $\mathrm{CMBCD}$, ie, dysglycemia, dyslipidemia, and hypertension when added to the standard of care.

\section{Abbreviations}

ABP, ambulatory blood pressure; ACE, angiotensin converting enzyme; AE, adverse event; AMPK, adenosine monophosphate kinase; ANCOVA, analysis of covariance; ANOVA, analysis of variance; ARB, angiotensin receptor blocker; AUC, area under curve; BMI, body mass index; BP, blood pressure; CCB, calcium channel blocker; CMBCD, cardiometabolic based chronic disease; CMD, cardiometabolic disease; CTRI, clinical trial registry of India; CVD, cardiovascular disease; DBP, diastolic blood pressure; DCGI, drug controller general of India; DSCF, Dwass-SteelCritchlow-Fligner; DSMB, data safety monitoring board; ECG, electrocardiogram; ETC, electron transport chain; FPG, fasting plasma glucose; GCP, good clinical practice; GGT, gamma-glutamyl transaminase; HBA1c, glycated hemoglobin; HDL, high density lipoprotein-cholesterol; HIV, human immunodeficiency virus; HOMA-IR, homeostasis model assessment insulin resistance; ICH, International council for Harmonization; IEC, institutional ethics committee; IR, insulin resistance; IRB, institutional review board; mITT, modified intention to treat; LDL, Low density lipoprotein-cholesterol; LOCF, last observation carried forward; MAP, mean arterial pressure; MRI, magnetic resonance imaging; MRS, 
magnetic resonance spectroscopy; RP, retinyl palmitate; SAD, single ascending dose; SAE, serious adverse event; SBP, systolic blood pressure; SD, standard deviation; SoC, standard of care; T2D, type 2 diabetes mellitus; TC, total cholesterol; TEAE, treatment emergent adverse event; TG, triglyceride; TSH, thyrotropin stimulating hormone; URTI, upper respiratory tract infection; UTI, urinary tract infection; WC, waist circumference.

\section{Data Sharing Statement}

Data will be available from the corresponding author upon request.

\section{Ethics Approval and Consent to Participate}

The study was initiated after obtaining the approval of the Drug Controller General of India (DCGI; F.No.12-196/09 DC, Dec 21, 2012), Independent/Institutional Ethics Committee (IEC) of each site. All subjects provided written informed consent before study procedures were commenced.

\section{Consent for Publication}

All authors have read and approved the final manuscript for submission.

\section{Acknowledgments}

The authors would like to acknowledge SIRO Clinpharm Pvt. Ltd. (CRO), Dr. Suchit Kumbhare, Dr. Amarinder Singh, and Dr. Vipin Bulani (Torrent Pharmaceuticals) for editorial assistance and administrative support. The authors also acknowledge CAMRRI trial collaborators (a list of participating investigators and institutions follows).

CAMRRI trial collaborators: list of participating investigator(s) and institution(s)

\begin{tabular}{|c|c|c|}
\hline $\begin{array}{l}\text { Site } \\
\text { No }\end{array}$ & Name of PI & Name and Address of Sites \\
\hline 01 & $\begin{array}{l}\text { Dr. Paramesh } \\
\text { Shamanna }\end{array}$ & Bangalore Clinisearch, No. 416, 4th Cross, 2nd Block, Kalyan Nagar, Bangalore 560043, Karnataka, India \\
\hline 02 & $\begin{array}{l}\text { Dr. Naveen } \\
\text { Jamwal }\end{array}$ & M. V. Hospital \& Research Centre, 314/30, Mirza Mandi, Chowk, Lucknow 226003, Uttar Pradesh, India \\
\hline 03 & $\begin{array}{l}\text { Dr. Shrikant } \\
\text { Deshpande }\end{array}$ & $\begin{array}{l}\text { Ashirwad Hospital \& Research Centre, Maratha Section, Near Jijamata Udyan, Ulhasnagar 42 I004, Maharashtra, } \\
\text { India }\end{array}$ \\
\hline 04 & Dr. K. D. Modi & Medwin Hospital, Raghava Ratna Towers, Chirag Ali Lane, Nampally, Hyderabad, Andhra Pradesh-50000I, India \\
\hline 05 & $\begin{array}{l}\text { Dr. Neeta } \\
\text { Deshpande }\end{array}$ & Belgaum Diabetes Centre, Ground \& Second Floor, Maruti Galli, Belgaum 59000I, Karnataka, India \\
\hline 06 & Dr. S. R. Arvind & Diacon Hospital, 359-360, 19th Main, Ist Block, Rajajinagar, Bangalore 5600I0, Karnataka, India \\
\hline 07 & $\begin{array}{l}\text { Dr. R. } \\
\text { Balamurugan }\end{array}$ & $\begin{array}{l}\text { Kovai Diabetes Speciality Centre \& Hospital, \#15, Vivekananda Road, Ram Nagar, Coimbatore 641009, Tamil Nadu, } \\
\text { India }\end{array}$ \\
\hline 08 & Dr. Sunil Gupta & Sunil's Diabetes Care n' Research Centre, 42, Lenda Park, Ramdas Peth, Nagpur 4400I0, Maharashtra, India \\
\hline 09 & Dr. Yogesh Kadam & $\begin{array}{l}\text { Inamdar Multispeciality Hospital, Research Department, Survey No. I5, Fatima Nagar, Wanowrie, Pune - } 4 \text { II 040, } \\
\text { Maharashtra, India }\end{array}$ \\
\hline 10 & $\begin{array}{l}\text { Dr. Sreenivasa } \\
\text { Murthy }\end{array}$ & $\begin{array}{l}\text { Lifecare Clinic \& Research Centre, \#2253, M. C. N. Complex, Kodigehalli Main Road, Sahakar Nagar, Bangalore } \\
\text { 560092, Karnataka, India }\end{array}$ \\
\hline 11 & $\begin{array}{l}\text { Dr. Mala } \\
\text { Dharmalingam }\end{array}$ & $\begin{array}{l}\text { Bangalore Endocrinology \& Diabetes Research Centre, \#35, 5th Cross, Malleswaram Circle, Bangalore 560003, } \\
\text { Karnataka, India }\end{array}$ \\
\hline
\end{tabular}


(Continued).

\begin{tabular}{|l|l|l|}
\hline $\begin{array}{l}\text { Site } \\
\text { No }\end{array}$ & Name of PI & Name and Address of Sites \\
\hline 12 & $\begin{array}{l}\text { Dr. Shivakumar B. } \\
\text { R. }\end{array}$ & $\begin{array}{l}\text { Cosmopolitan Medical Centre, \#10, 5th Main, Mariappa Road, Kullappa Circle, Kammanahalli, St. Thomas Town } \\
\text { Post, Bangalore 560084, Karnataka, India }\end{array}$ \\
\hline 13 & $\begin{array}{l}\text { Dr. Shreerang } \\
\text { Godbole }\end{array}$ & $\begin{array}{l}\text { Institute for Treatment \& Research in Diabetes \& Endocrinology, 6, Poonam Arcade, I I70/II, Revenue Colony, J. M. } \\
\text { Road, Shivajinagar, Pune 4I I005, Maharashtra, India }\end{array}$ \\
\hline 14 & Dr. Vinayak Kale & Lokmanya hospital, sector 24, Tilak road, Pradhikaran, Nigdi, Pune-4I I044, Maharashtra, India \\
\hline 16 & Dr. Shailesh Pitale & $\begin{array}{l}\text { Pitale Diabetes \& Hormone Centre, Ground Floor, Shriman Complex, Near Lokmat Square, Nagpur 4400I2, } \\
\text { Maharashtra, India }\end{array}$ \\
\hline 17 & Dr. V. Mohan & $\begin{array}{l}\text { Dr. Mohan's Diabetes Specialities Centre (Madras Diabetes Research Foundation), \#4 \& \#6B, Conran Smith Road, } \\
\text { Gopalapuram, Chennai 600086, Tamil Nadu, India }\end{array}$ \\
\hline
\end{tabular}

\section{Author Contributions}

All authors contributed significantly to the conception, study design, acquisition of data, or analysis and interpretation of data; participated in drafting or revising the article critically; agreed to submit to the current journal; gave final approval of the version to be published; and agreed to be accountable for all aspects of the work.

\section{Funding}

This study was funded by Torrent Pharmaceuticals Ltd.

\section{Disclosure}

Deepa Joshi, Prashant GJ, Shohini Ghosh, Anookh Mohanan and Chaitanya Dutt report being employees of Torrent Pharmaceuticals Ltd, Dr Shohini Ghosh reports grants from Biotechnology Industry Research Assistance Council (BIRAC)/Dept. of Biotechnology (DBT), during the conduct of the study. Dr Anookh Mohanan reports grants from Biotechnology Industry Research Assistance Council (BIRAC) of Department of Biotechnology (DBT), Government of India (received financial support (partial) from BIRAC (DBT) in the form of soft loan (major) and grant (minor) for this trial), during the conduct of the study. Dr Shashank Joshi reports advisory for Torrent, during the conduct of the study; speaker for Eli Lilly, Abbott, Boehringer Ingelheim, MSD, Novo Nordisk, PHFI, Micro Labs, and Bayer Zydus, advisory for Astra Zeneca, USV, Marico, Sanofi, Zydus Cadila, Twin Health, and Franco Indian, and speaker and advisory for Roche Diabetes Care, outside the submitted work. Professor Subhankar Chowdhury reports personal fees from Healtheon, Intas Pharmaceutical, and Novo Nordisk, outside the submitted work. Dr Chaitanya Dutt reports grants from Biotechnology Industry Research Assistance Council (BIRAC) of Department of Biotechnology (DBT), Government of India, during the conduct of the study (BIRAC/DBT has partially funded this study with a mix of soft loan and grant); and in addition has a patents IN254907, US8143424 B2, EP2061766B1, and WO2008/149379A2 issued not licensed to any third party. The authors report no other potential conflicts of interest in this work.

\section{References}

1. Mechanick JI, Farkouh ME, Newman JD, Garvey WT. Cardiometabolic-based chronic disease, addressing knowledge and clinical practice gaps. $J$ Am Coll Cardiol. 2020;75(5):539-555. doi:10.1016/j.jacc.2019.11.046

2. Mechanick JI, Garber AJ, Grunberger G, Handelsman Y, Garvey WT. Dysglycemia-based chronic disease: an American association of clinical endocrinologists position statement. Endocr Pract. 2018;24(11):995-1011. doi:10.4158/PS-2018-0139

3. Kalra S, Unnikrishnan AG, Baruah MP, Sahay R, Bantwal G. Metabolic and energy imbalance in dysglycemia-based chronic disease. Diabetes Metab Syndr Obes. 2021;14:165-184. doi:10.2147/DMSO.S286888 
4. Iyengar SS, Narasingan SN, Gandhi P, et al. Risk factors, comorbiditiEs and atherogenic dysLipidaemia in Indian YOUNG patients with dyslipidaemia attending hospital/clinic: REAL YOUNG (dyslipidaemia) study. J Fam Med Prim Care. 2020;9(8):4156-4164. doi:10.4103/jfmpc. jfmpc_546_20

5. Gupta P, Singh K, Shivashankar R, et al. Healthcare utilisation and expenditure patterns for cardio-metabolic diseases in South Asian cities: the CARRS Study. BMJ Open. 2020;10(9):e036317. doi:10.1136/bmjopen-2019-036317

6. Gonzalez-Rivas JP, Mechanick JI, Infante-Garcia MM, et al. Prevalence of Dysglycemia-Based Chronic Disease (DBCD) in European population: a new paradigm to address diabetes burden. the KARDIOVIZE study. Endocr Pract. 2020. doi:10.1016/j.eprac.2020.10.003

7. Cioffi F, Zambad SP, Chhipa L, et al. TRC150094, a novel functional analog of iodothyronines, reduces adiposity by increasing energy expenditure and fatty acid oxidation in rats receiving a high-fat diet. FASEB J. 2010;24(9):3451-3461. doi:10.1096/fj.10-157115

8. Silvestri E, Glinni D, Cioffi F, et al. Metabolic effects of the iodothyronine functional analogue TRC150094 on the liver and skeletal muscle of high-fat diet fed overweight rats: an integrated proteomic study. Mol Biosyst. 2012;8(7):1987-2000. doi:10.1039/c2mb25055a

9. Zambad SP, Munshi S, Dubey A, et al. TRC150094 attenuates progression of nontraditional cardiovascular risk factors associated with obesity and type 2 diabetes in obese ZSF1 rats. Diabetes Metab Syndr Obes. 2011;4:5-16. doi:10.2147/DMSOTT.S15323

10. Joshi D, Jamadarkhana P, Kumbhare S, et al. Safety, tolerability, and pharmacokinetics of a novel mitochondrial modulator, TRC150094, in overweight and obese subjects: a randomized phase-I clinical trial. Front Pharmacol. 2021;12:2465. doi:10.3389/fphar.2021.729424

11. van der Valk F, Hassing C, Visser M, et al. The effect of a diiodothyronine mimetic on insulin sensitivity in male cardiometabolic patients: a double-blind randomized controlled trial. PLoS One. 2014;9(2):e86890. doi:10.1371/journal.pone.0086890

12. Fagard RH, Celis H, Thijs L, et al. Daytime and nighttime blood pressure as predictors of death and cause-specific cardiovascular events in hypertension. Hypertension. 2008;51(1):55-61. doi:10.1161/HYPERTENSIONAHA.107.100727

13. Vial G, Detaille D, Guigas B. Role of mitochondria in the mechanism(s) of action of metformin. Front Endocrinol. 2019;10. doi:10.3389/ fendo.2019.00294

14. Detaille D, Vial G, Borel A-L, et al. Imeglimin prevents human endothelial cell death by inhibiting mitochondrial permeability transition without inhibiting mitochondrial respiration. Cell Death Discov. 2016;2(1):15072. doi:10.1038/cddiscovery.2015.72

Diabetes, Metabolic Syndrome and Obesity: Targets and Therapy

Dovepress

\section{Publish your work in this journal}

Diabetes, Metabolic Syndrome and Obesity: Targets and Therapy is an international, peer-reviewed open-access journal committed to the rapid publication of the latest laboratory and clinical findings in the fields of diabetes, metabolic syndrome and obesity research. Original research, review, case reports, hypothesis formation, expert opinion and commentaries are all considered for publication. The manuscript management system is completely online and includes a very quick and fair peer-review system, which is all easy to use. Visit http://www.dovepress. com/testimonials.php to read real quotes from published authors.

Submit your manuscript here: https://www.dovepress.com/diabetes-metabolic-syndrome-and-obesity-targets-and-therapy-journal 